\title{
Bacterial strains isolated from cedar wood improve the mycelial growth and morphology of white rot fungus Phlebia brevispora on agar and liquid medium
}

\author{
Joy L. Harry-asobara ${ }^{1} \cdot$ Ichiro Kamei $^{2}$
}

Received: 27 November 2017 / Accepted: 15 March 2018 / Published online: 18 April 2018

(C) The Japan Wood Research Society 2018

\begin{abstract}
Growth enhancement of white rot fungus Phlebia brevispora TN3F by two bacterial strains TN3W-8 and TN3W-14 which showed high identity with genus Pseudomonas and Enterobacter, respectively, was investigated in liquid and solid media at different glucose concentrations. The white rot fungus P. brevispora $\mathrm{TN} 3 \mathrm{~F}$ and the bacterial strains were isolated from same white rot-decayed cedar wood from the Tano Forest Science Station at University of Miyazaki. Confrontational assay between the fungus and the bacterial strains revealed a fungal growth enhancement phenomenon, in the direction of the bacterial cells, even without direct contact. This enhancement increased with decrease of glucose concentration, $0.5 \%$ glucose offering comparatively the most mycelial growth. In potato extract (PE) medium at $0.5 \%$ glucose concentration, along with mycelial growth enhancement and morphological change of $P$. brevispora TN3F, growth and morphological enhancement of fungus TMIC33929, another strain of P. brevispora, was achieved by the bacterial strain TN3W-14, although TMIC33929 originated from a different environment. Outside few reports of a positive interaction between white rot fungi and other microorganisms, this is a first report of such positive interaction in liquid medium. Furthermore, this also is the first report of a single bacterium having potential to positively affect mycelia growth of different strains of a white rot fungus.
\end{abstract}

Keywords White rot fungus $\cdot$ Phlebia brevispora $\cdot$ Growth enhancement $\cdot$ Growth-promoting bacteria

\section{Introduction}

Wood is decomposed by a variety of biological agents, including fungi, bacteria, and insects. Fungi colonize wood and degrade cell wall components to form brown, soft or white rot. The mycelium of lignin-degrading basidiomycetes, referred to as white rot fungi, secretes extracellular enzymes that break down lignin [1]. Lignin is structurally

Part of this article was presented at the 67th Annual Meeting of the Japan Wood Research Society, March 2017, Fukuoka Japan.

Ichiro Kamei

kamei@cc.miyazaki-u.ac.jp

1 Graduate School of Agriculture and Engineering, University of Miyazaki, 1-1, Gakuen-kibanadai-nishi, Miyazaki 889-2192, Japan

2 Division of Forest Science, Department of Forest and Environmental Sciences, Faculty of Agriculture, University of Miyazaki, 1-1, Gakuen-kibanadai-nishi, Miyazaki 889-2192, Japan similar to many organic pollutants. Therefore, in laboratory studies, many ligninolytic fungi have exhibited great potential for use in the degradation of recalcitrant organic matter [2]. However, the success of bioremediation projects has been limited by the failure to remove toxic compounds from contaminated sites [3]. One of the reasons of this failure might be the lack of the relationship between exogenous fungus and indigenous microbial consortia in contaminated site.

Studies have shown that bacteria may have a synergistic or antagonistic effect on other microorganisms [4, 5], and the practical relevancies of fungal-bacterial interactions to an exceptionally diverse variety of fields, including agriculture, forestry, environmental protection, food processing, biotechnology, medicine, dentistry, etc., have been reported [4, 6-8]. Although bacteria exist in rotten wood and their involvement in wood rotting had been discussed $[9,10]$, other possible interactions have not been explored between wood-degrading white rot basidiomycetes and bacteria. More especially in the field of environment, efforts are being made to integrate strains of different microorganisms for synergistic bioremediation effects. To enhance this 
needed synergy, an understanding of specific nutrient and growth interactions between bacteria and ligninolytic fungi is important.

Wood rot fungus Phlebia brevispora is one of the most studied species which has degradation ability for organohalogen compounds such as polychlorinated biphenyls, polychlorinated dioxins, and organohalogen pesticides [11-13]. To enhance its bioremediation traits, it is pertinent to control the growth of this fungus. Recently, we proved that some coexisting bacteria, which were isolated from rotten wood with white rot fungi, possess enhancement activity for mycelial growth of Stereum sp. [14] and wood degradation by Trametes versicolor [15]. These results gave the hypothesis that some bacteria which were co-isolated with P. brevispora also have synergistic activity for the fungal growth.

To test this hypothesis, in this study, isolation and characterization of co-isolated bacteria with $P$. brevispora was carried out, and the bacterial strains subsequently co-cultured with the fungal strains. The objective of present study was, therefore, to test bacterial enhancement of the fungal mycelium in liquid medium. Our results clearly indicated, for the first time, mycelia growth enhancement of $P$. brevispora by co-cultured bacteria in liquid medium.

\section{Materials and methods}

\section{Isolation of fungal mycelia and the coexisting bacteria}

From Tano Forest Science Station at University of Miyazaki, white rot-decayed cedar wood samples and a basidiomycetous fruit body were collected from same wood. The decayed xylem was collected to approximately $2 \mathrm{~cm}$ depth after removal of the bark. For isolation of cultivable bacteria, wood chips were placed in $10 \mathrm{~mL}$ sterile water, vortex mixed and the resulting suspension dilution plated in $0.1 \mathrm{~mL}$ aliquots onto R2A agar (peptone $0.5 \mathrm{~g} / \mathrm{L}$, yeast extract $0.5 \mathrm{~g} / \mathrm{L}$, casamino acids $0.5 \mathrm{~g} / \mathrm{L}$, glucose $0.5 \mathrm{~g} / \mathrm{L}$, soluble starch $0.5 \mathrm{~g} / \mathrm{L}, \mathrm{K}_{2} \mathrm{HPO}_{4} 0.3 \mathrm{~g} / \mathrm{L}, \mathrm{MgSO}_{4} \cdot 7 \mathrm{H}_{2} \mathrm{O} 0.05 \mathrm{~g} / \mathrm{L}$, sodium pyruvate $0.3 \mathrm{~g} / \mathrm{L}$, Agar $15 \mathrm{~g} / \mathrm{L}$ ). Available bacterial colonies were isolated after cultures were incubated for 2-7 days at $25^{\circ} \mathrm{C}$. The fungal mycelia were isolated on the agar medium with beech wood powder as the sole carbon source and on the basis of formation of a reddish-colored zone in the culture medium resulting from guaiacol oxidation, type of rot was evaluated. The isolated mycelia were maintained on potato dextrose agar (PDA; Difco Laboratories). Bacterial strains which showed enhancement effect for mycelial growth of isolated fungus were selected preliminary by confrontational assay on PDA according to our previous study [14]. The incubation of mycelium and measurement of mycelial growth were carried out as described "Confrontational assay" section.

\section{Identification of fungus and bacteria}

Bacterial total DNAs were isolated using ISOPLANT (Nippon Gene, Tokyo, Japan). A polymerase chain reaction (PCR) was carried out to amplify the 16S rRNA genes using the known primers $27 \mathrm{f}$ and $1492 \mathrm{r}$ [16]. PCR and sequence were done according to our previous paper [14]. Then obtained conserved sequences were compared with those in the GenBank database using the BLAST search engines in the DNA Data Bank of Japan (DDBJ, Tokyo, Japan). On the other hand, the 5.8S rRNA gene sequence of fungal strain $\mathrm{TN} 3 \mathrm{~F}$ was matched with that of $P$. brevispora.

\section{Confrontational assay}

To determine the effect of glucose concentration on the enhancement of mycelial growth of $P$. brevispora by selected bacterial strains, potato extract agar (PEA) medium was prepared. Potato extract was prepared by boiling $200 \mathrm{~g}$ of fresh potato (Solanum tuberosum) with $1 \mathrm{~L}$ of pure water for $1 \mathrm{~h}$ (pH 6.4). Then the different amount of glucose (final concentrations were 0 to $2 \%$ ) and $25 \mathrm{~g}$ of agar were added and subsequently autoclaved. After cooling, $9 \mathrm{~mm}$ diameter fungal disks taken from the margins of 1-week-old fungal colonies on PDA medium were inoculated. The different glucose concentrations tested were $0,0.5,1,1.5$ and $2 \%$. Bacterial strains were then inoculated using sterile inoculation loops, and placed $2.5 \mathrm{~cm}$ from the fungal disks. Four Petri dishes of each glucose concentration were incubated at $25{ }^{\circ} \mathrm{C}$ in the dark. Mycelial growth was measured from the 2 nd day onward after inoculation. The radii of the fungal colonies in the direction of the bacterial colony, and also away from the bacterial colony were measured daily for 7 days. For measurement away from the bacterial colonies, daily average of the three-directional radii was calculated. Student's $t$ tests or Mann-Whitney $u$ tests was done to determine any significant difference between the groups of mycelial growth. Differences between means at the 5\% confidence level $(p<0.05)$ were considered to be statistically significant.

\section{Co-culturing in liquid medium}

To determine the effect of the growth-promoting bacteria in liquid medium for white rot fungus $P$. brevispora TMIC33929, first, P. brevispora TN3F and the bacteria strains TN3W-8 and TN3W-14 were co-cultivated using potato extract (PE) medium at different glucose concentrations. Growth medium was prepared as described for solid medium, except that here no agar was added. For TN3F and each of TN3W-8 and TN3W-14 co-cultivation, bacterial 
cells were pre-incubated for 2 days, and then $1 \mathrm{~mL}$ of preincubated bacterial culture was inoculated into $19 \mathrm{~mL}$ of new PE medium in 50-mL Erlenmeyer flasks. Mycelial disks (9 $\mathrm{mm}$ diameter) were taken from the margins of 1-week-old fungal colonies and inoculated into the liquid medium with bacteria. Four flasks for each glucose concentration were incubated in the dark at $25^{\circ} \mathrm{C}$ on a $120 \mathrm{rpm}$ rotary shaker. Daily fungal growth was determined for 9 days according to the dry weights of mycelia. For the good result obtained at $0.5 \%$ glucose concentration, this concentration was used for co-cultivation of $P$. brevispora TMIC33929 with each of the bacterial strains, following the process described above.

Mycelia were collected by filtration using 1G2 glass filter (pore size: $40-100 \mu \mathrm{m}$ ). Initial wet and dry weights of the glass filter were determined. To evaluate adsorption of bacterial cell to glass filter, the bacterial culture incubated for 4 days was filtrated and the dry weight was determined. Additionally, adsorption of bacterial cell to fungal mycelium was also evaluated as follows: the mycelium of $P$. brevispora TMIC33929 which was incubated for 7 days was collected by centrifugation $(5000 \times \mathrm{g}, 10 \mathrm{~min})$ in 50 -mL centrifugation tube. The supernatant was removed, and bacterial culture previously incubated for 4 days was added to the separated mycelium. Then the centrifugation tube (containing bacterial culture and fungal mycelium) was incubated for $1 \mathrm{~h}$ at $25{ }^{\circ} \mathrm{C}$ on the rotary shaker $(120 \mathrm{rpm})$. After incubation, the mixture of bacterium and fungal mycelium was filtrated and the dry weight of fungal mycelium determined.

\section{Mycelial growth enhancement by cell-free culture of bacterium}

To confirm whether bacterial cells produced some enhancement factor into the culture or not, culturing test using cell-free culture was carried out. The bacterial cells were cultured in PE medium at $0.5 \%$ glucose concentration for 5 days, and then the cells were removed by centrifugation at $12,000 \mathrm{rpm}$ for $10 \mathrm{~min}$. Obtained supernatant was filtered using a $0.22-\mu \mathrm{m}$ Millex-HP sterile filter, and then the fungal mycelium was inoculated. To ensure that no remnants of bacterial cells contaminated the supernatant, ampicillin $(1 \mathrm{mg} / \mathrm{mL})$ was added to the cell-free culture. The flasks were incubated in the dark at $25{ }^{\circ} \mathrm{C}$ on a $120 \mathrm{rpm}$ rotary shaker for 9 days.

\section{Results and discussion}

Twenty-seven cultivable bacterial colonies (TN3W-1 to TN3W-27) were isolated arbitrarily from suspension dilutions of the decayed wood after plating onto R2A agar, and confrontational assays were conducted. The mycelial growth of P. brevispora strain TN3F on PDA with or without bacterial cells was compared. Among the 27 bacterial isolates, 7 had enhancement effects on the growth of $P$. brevispora strain TN3. The selected seven bacterial isolates showed difference ( $\geq 10 \mathrm{~mm} /$ day) between mycelial growth in the direction of bacterial cells and growth without bacterial cells (data not shown). Out of the 7 growth enhancing bacteria; we selected two bacterial strains, TN3W-8 and TN3W-14 for further study. The partial sequences of $16 \mathrm{~S}$ rRNA gene from bacterial strains TN3W-8 (1530 bp) and TN3W-14 (1535 bp) showed high identity to genus Pseudomonas and Enterobacter, respectively. TN3W-8 showed highest identity (99\%, 1523/1529 bp) to Pseudomonas putida KT2440 (LT799039) and TN3W-14 showed highest identity $(98 \%, 1515 / 1534$ bp) to Enterobacter cloacae AR 0065 (CP020053). On the other hand, the 5.8S rRNA gene sequence of fungal strain $\mathrm{TN} 3 \mathrm{~F}$ was matched with that of P. brevispora.

White rot fungus $P$. brevispora, a species of the Phlebia genera, is one of the good candidates for bioremediation of contaminated sites by aromatic compounds because of its ability to degrade several aromatic contaminants such as dioxins [12] and PCBs [11]. We hypothesized that its bioremediation trait would be improved by co-cultivation with bacterial strains capable of improving its growth, especially in liquid medium. Murray and Woodward [17] reported that bacterial addition increased weight loss of wood cubes by $200 \%$ relative to cultures lacking bacteria. Recently, Kamei [15] reported that the bacterial strains Enterobacter sp. were isolated frequently from rotting wood with white rot fungus $T$. versicolor, and co-cultivation of T. versicolor and Enterobacter sp. TN6W-27 on wood powder enhanced the degradation of wood powder. In present study, the fact that another bacterial strain TN3W-14 classified to genus Enterobacter was isolated from same rotten wood as P. brevispora is interesting, and calls for determination of any possible interaction between them.

Confrontational assay for $P$. brevispora $\mathrm{TN} 3 \mathrm{~F}$ and bacterial strains TN3W-8 and TN3W-14 at different glucose concentrations revealed enhancement of mycelial growth without contact with bacterial cells. Compared with the control (P. brevispora $\mathrm{TN} 3 \mathrm{~F}$ only) at different glucose concentrations, bacteria strains TN3W-8 and TN3W-14 significantly improved the mycelial growth of the fungus at all glucose concentrations except at $0 \%$. The enhancement tended to increase along with the decrease of glucose concentration, and then in all, $0.5 \%$ offered comparatively, the most mycelia growth enhancement. At $0 \%$ glucose, bacteria strains TN3W-8 and TN3W-14 inhibited the mycelial growth of $P$. brevispora $\mathrm{TN} 3 \mathrm{~F}$ significantly. This suggests that the bacterial strains would produce some inhibiting compounds to fungal growth in no glucose condition for survival. Away from the bacteria cells and compared with the control (except at $0 \%$ glucose), the bacterial cells gave comparable 
enhancement of mycelial growth at $0.5 \%$ glucose (Fig. 1b). However, statistically, bacterial strain TN3W-8 offered significant mycelial growth at this glucose concentration. This suggests that certain compounds might have been produced at this concentration by the bacteria strains which improved fungal mycelia growth.

To identify the effect of bacterial co-culturing in liquid culture and the specificity of bacterial co-culturing with $P$. brevispora strains with different origin, each of bacterial strains TN3W-14 and TN3W-8 was co-cultured with either of $P$. brevispora strain TN3F or strain TMIC33929, strain TMIC33929 being obtained from a dissimilar environment. Figure 2 shows the photographs of mycelial growth in liquid culture with or without bacteria. In present liquid condition, mycelia of TN3F and TMIC33929 showed the formation of a compact globular shape and poor growth around mycelial disk (Fig. 2a, d). However, active mycelial spread was observed with co-cultivation of fungal strain TN3F with bacterial strains TN3W-14 and TN3W-8 (Fig. 2b, c). These results indicate that fungal growth enhancement activity of bacteria works also in liquid condition. For P. brevispora strain TMIC33929, active mycelial spread was only induced by bacterial strain TN3W-14 (Fig. 2e). Time course of mycelial growth and morphological change around inoculated mycelial disk in liquid medium is shown in Fig. 2f. After 4 days incubation, compact globular shape (pellet) was broken and unbound, then active mycelia spread was observed in bacterial co-culturing. These results indicate that Enterobacter $\mathrm{sp}$. TN3W-14 enhances the mycelial growth of not only co-isolated strain of $P$. brevispora TN3F, but also that of strain TMIC33929 from a dissimilar environment.

This mycelial growth enhancement seemed to be affected by a morphological change from pellet to filamentous form. Pellet morphology is well known in submerged cultures of mycelial microorganisms [18]. Although pellet morphology allows easier mixing, growth is restrained due to substrate limitation in the region of the dense pellet core. In present study, P. brevispora showed the pellet form with low mycelial growth in liquid culture under $120 \mathrm{rpm}$ rotary shaking (Fig. 2). Bacterial co-cultivation seemed to dissolve this
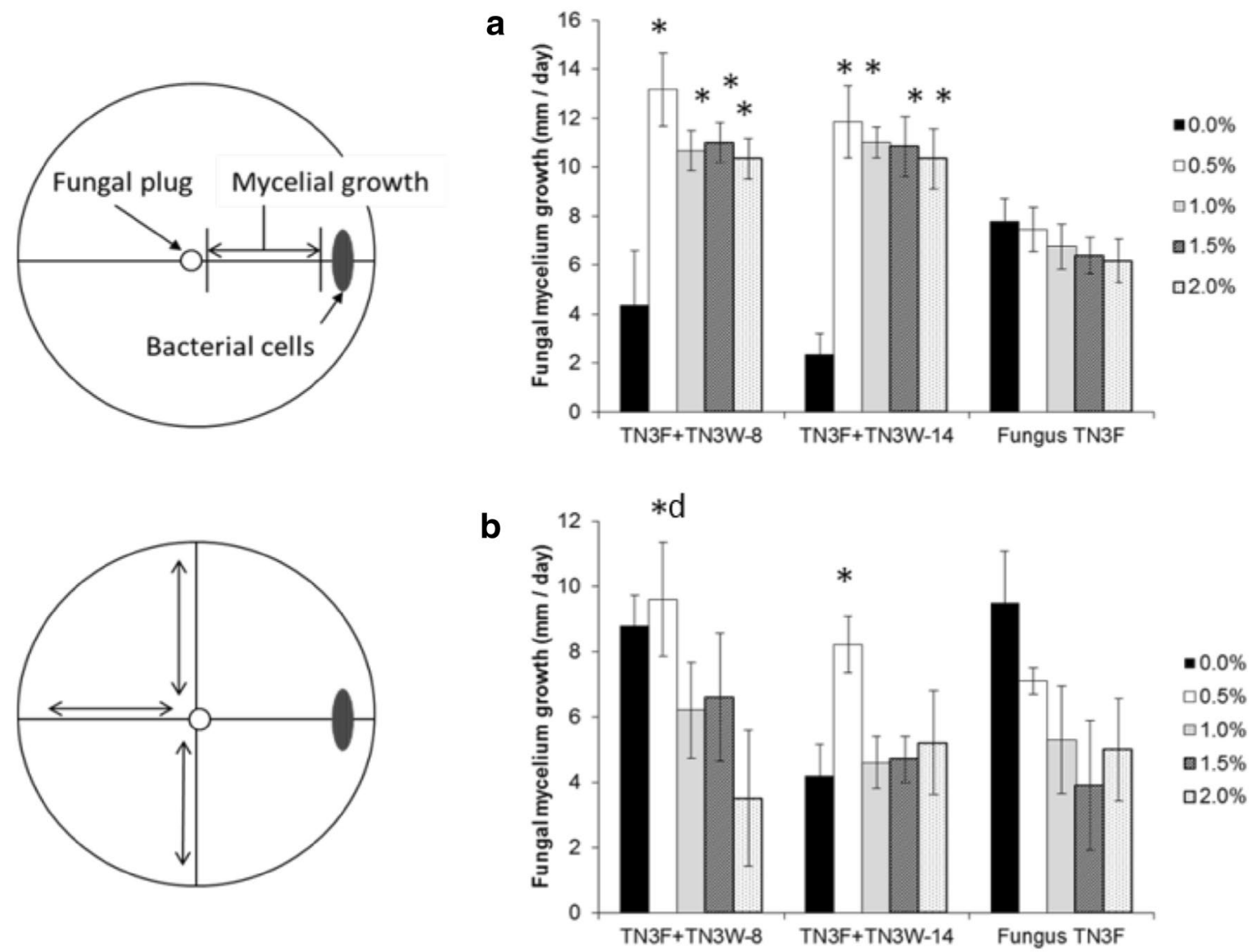

Fig. 1 Mycelial growth of Phlebia brevispora TN3F in confrontational assay with co-cultivated bacteria strains TN3W-8 and TN3W14 on PDA medium. Graphs $\mathbf{a}$ and b represent mycelia growth towards bacteria cells and away from bacteria cells, respectively. Inoculation positions of fungus and bacteria, as well as mycelia growth measurement positions are illustrated beside the corresponding graph. Asterisks indicate samples significantly different from the control, Student $t$ tests, $p<0.05$; letter d (Fig. 1b) indicates sample significantly different from the control, Mann-Whitney $u$ test, $p<0.05$. Data are means $\pm \mathrm{SD}$ of four samples 

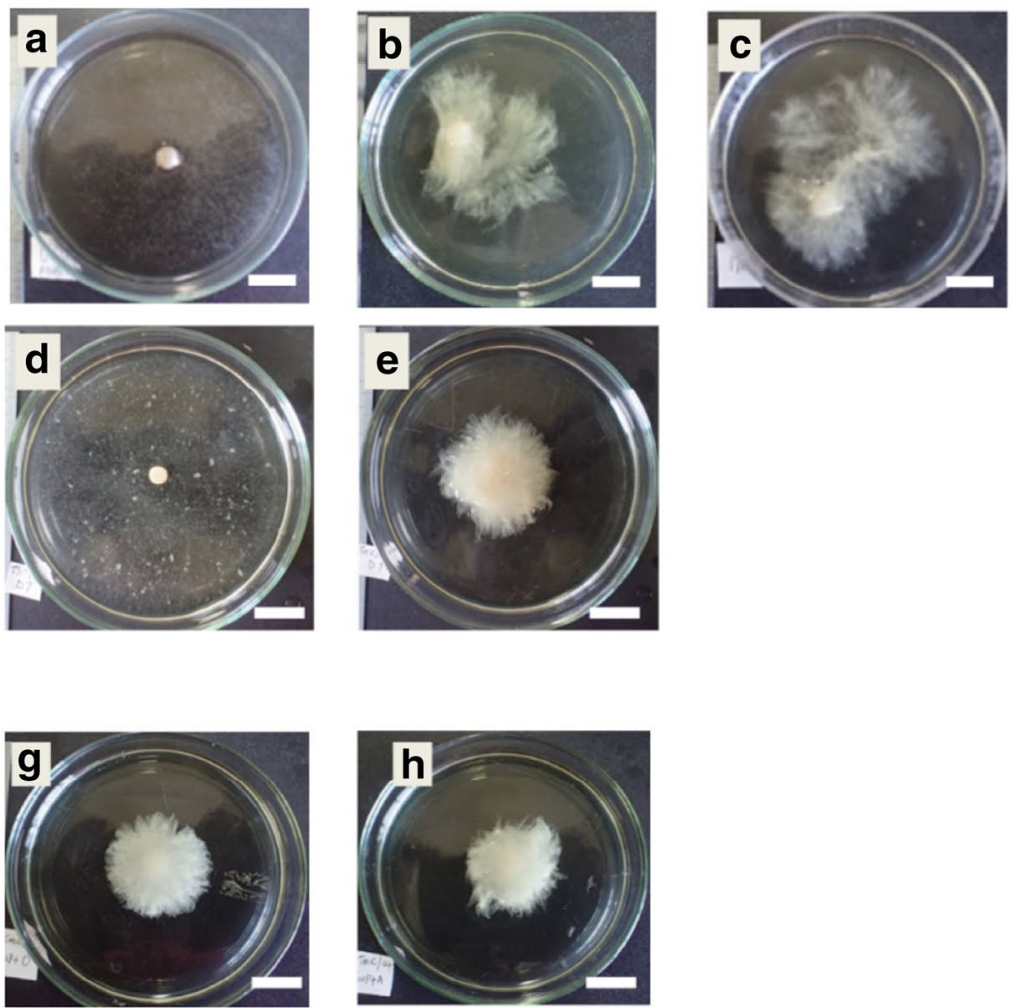

Fig. 2 Morphological changes of Phlebia brevispora strains TN3F or TMIC33929 mycelium with co-cultivated bacteria strains in liquid medium. a TN3F only, b TN3F with TN3W-8, c TN3F with TN3W14, d TMIC33929 only, e TMIC33929 with TN3W-14. Photos f show the daily transformations in the culture of P. brevispora TMIC33929

pellet form, and then the mycelial growth was enhanced (Figs. 2, 3). Recently, many researchers reported that morphological engineering of filamentous fungi by the supplementation of inorganic microparticles to fungal cultures stimulate growth of these organisms as well as biosynthesis of enzymes and chemicals [18]. Driouch et al. [19] reported that addition of microparticles to the culture with Aspergillus niger led to the formation of freely dispersed mycelium. Therefore, in present study, bacterial cell-free culture was prepared to understand the effect of bacterial cell. In bacterial cell-free culture of Enterobacter sp. TN3W-14, enhancement of mycelial growth of strain TMIC33929 was observed (Fig. 2g, h). This result indicates obviously that Enterobacter $\mathrm{sp}$. TN3W-14 produces some chemicals for morphological change and enhancement of mycelial growth of $P$. brevispora. Mycelia growth in liquid culture is shown in Fig. 3. To evaluate the adsorption of bacterial cells to mycelia of $P$. brevispora TMIC33929, the dry weight of bacterial cells, and of mycelia, after fungal incubation with bacteria for $1 \mathrm{~h}$ on glass filter were determined (Fig. 3b). Although the residual bacterial cells were slightly observed on glass filter, the adsorption of bacterial cells to glass filter, and to fungal mycelium, was minimal. Also, as observed

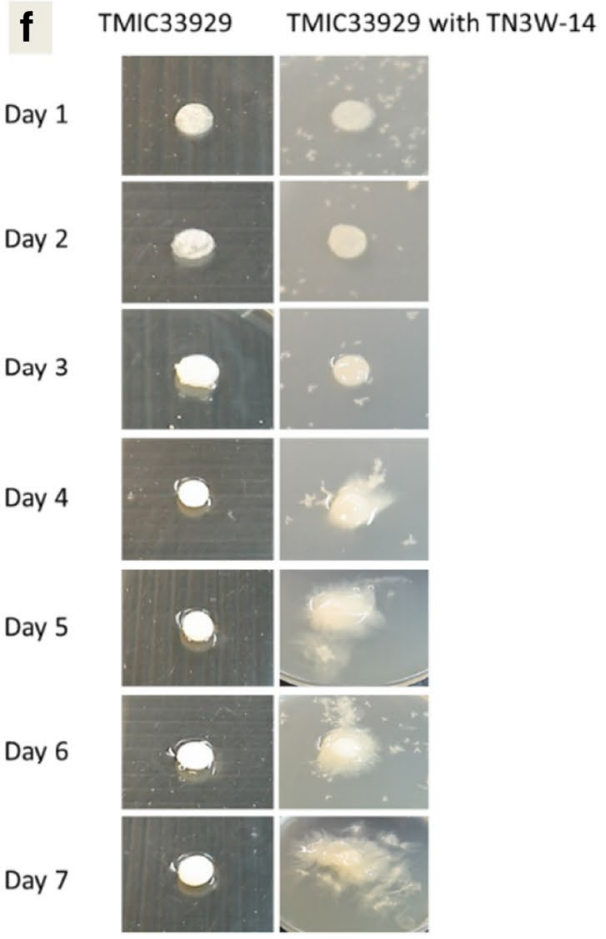

as influenced by the presence of bacterial strain TN3W-14, g TMIC33929 in TN3W-14 cell-free culture without added ampicillin, h TMIC33929 in TN3W-14 cell-free culture with added ampicillin. Bar; $2 \mathrm{~cm}$. Mycelial growth photos except $\mathrm{f}$ were taken in glass Petri dishes for clarity

for mycelium of $P$. brevispora TN3F when co-inoculated with the bacterial strains in liquid medium, the growth of TMIC33929 significantly increased in the presence of the bacterial strains compared with the control from day 5 of incubation (Fig. 3). Bacterial strain TN3W-14, however, offered significantly greater growth enhancement to TMIC33929 than did TN3W-8, as was the case of morphological enhancement.

Although effects of bacteria on fungal growth have been documented in a number of settings including in vitro studies of mycorrhizal fungi $[20,21]$ and clinically relevant bacterial-fungal interactions [22,23], very few reports exist on the improvement of growth of wood-rotting fungi by bacteria. No report exists of single bacterial strains promoting the mycelial growth of similar fungal strains isolated from different environment. In a recent study, Kamei et al. [14] reported on a positive interaction between a white rot fungus Stereum $\mathrm{sp}$. and its coexisting bacterium on a PDA medium. Fungi are grown routinely on agar media for identification. For bioremediation or even DNA extraction, however, preparation of fungi typically involves growing cultures in liquid media. Yet many fungal strains grow poorly in liquid media forming pellets, thus the need to formulate new media to 
Fig. 3 Mycelial growth of Phlebia brevispora TMIC33929 with bacteria strains TN3W-14 and $\mathrm{TN} 3 \mathrm{~W}-8$. a growth in liquid medium, b bacterial adsorption test on mycelia. Asterisks indicate samples significantly different from the control, Student $t$ tests, $p<0.05$. Data are means \pm SD of four samples
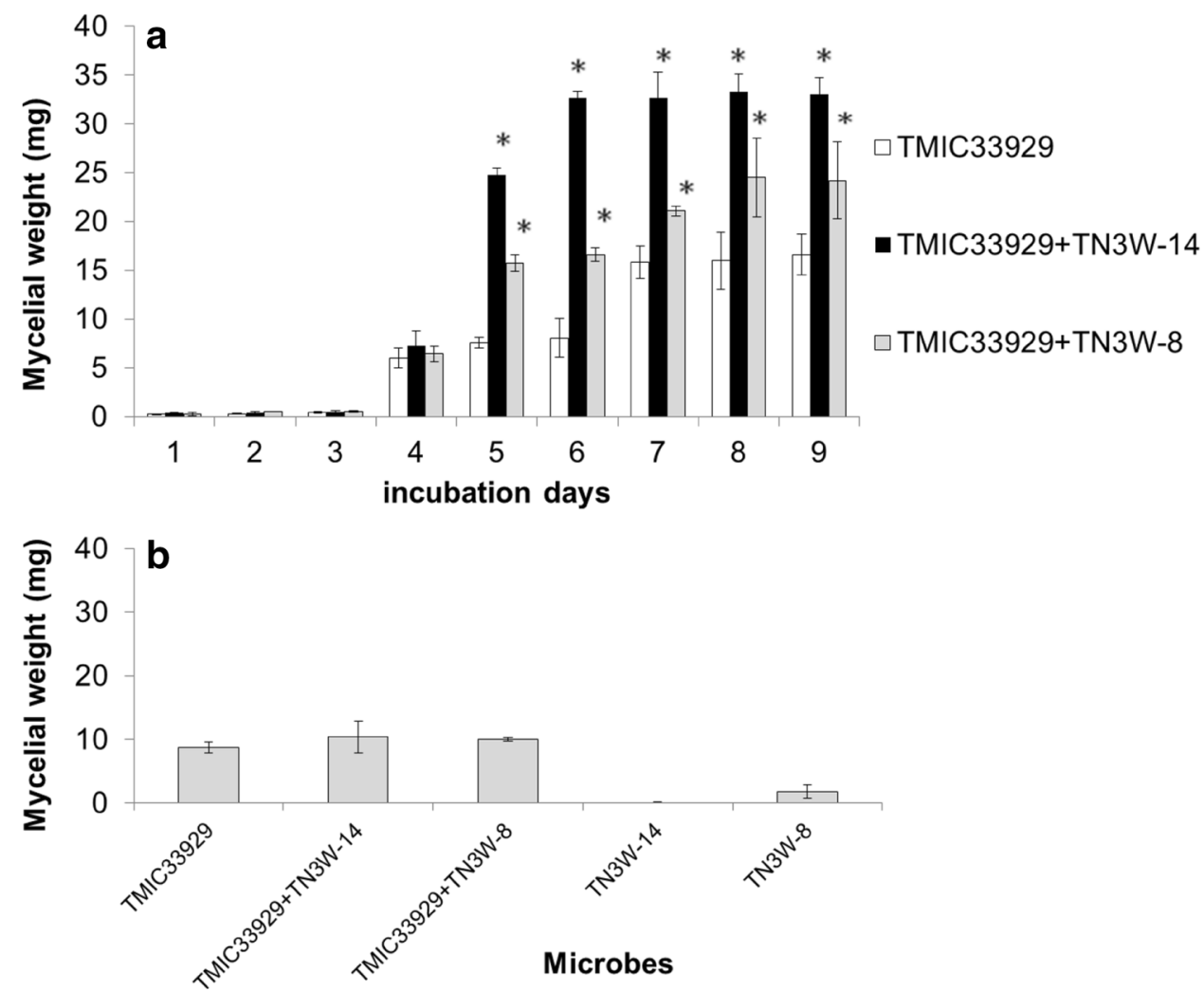

determine suitable growth requirements for liquid culture. In this study, although the bacterial strains further enhanced mycelial growth of the white rot fungi in the solid medium, the fungal strains could still grow unassisted. But in the liquid medium, they only formed pellets in axenic cultures. Mycelial growth could only be achieved when co-cultivated with the bacterial strains.

The physiological significance of bacteria that co-exist with white rot fungi has not been understood. Most attention has been given to the suppressive effects of bacterial volatiles on soil eukaryotes that are harmful to agricultural crops such as plant pathogenic fungi [5, 6, 24]. In present study, although specific compounds produced by bacteria strains TN3W-8 and TN3W-14 viewed to be responsible for the enhancement of growth and morphology of the mycelia of the white rot fungus $P$. brevispora strains TN3F and TMIC33929 were not identified, the roles of microbial volatile organic compounds in positive and antagonistic interactions between rhizobacteria and mycorrhizal fungi and their ecological significance have been described [25]. On the positive interactions, some growth-promoting compounds such as auxofuran, thiamine, ketones, and methylketones $[10,26]$ produced by mycorrhizal helper bacteria have been reported, even though the mechanism by which they improve mycelia growth is not yet certain. Our study, however, indicated positive interaction of white rot fungus $P$. brevispora TN3F and isolated bacteria strains. Furthermore, the isolated bacteria strain TN3W14 identified as Enterobacter showed ability to improve both growth and morphology of a strain of P. brevispora TMIC33929 from dissimilar environment. This is the first of such report of a single bacterial strain promoting the growth of different strains of a wood rot fungus. Also, the potential growth phenomenon and morphological enhancement of the white rot fungi by the bacteria strains were highlighted. Further study is required to understand the significance of these growth interactions on the degradative traits of the white rot fungus $P$. brevispora.

\section{Conclusion}

Growth-promoting bacteria of wood rot fungus $P$. brevispora, Pseudomonas sp. TN3W-8 and Enterobacter sp. TN3W-14 were isolated and identified. The growth enhancement was observed not only on the agar medium but also in potato extract medium at varying glucose concentrations. Especially, Enterobacter sp. TN3W-14 enhanced the growth of not only co-isolated P. brevispora strain TN3F, but also that of P. brevispora strain TMIC33929 which was obtained from a dissimilar environment. Here, we propose first the possibility of growth management of $P$. brevispora, a white rot basidiomycetes, by co-culturing with bacterial strains. 
Acknowledgements The authors would like to thank Taichi Motoda and Naoto Ozeki for technical assistance with the experiments. This work was supported in part by a Grant-in-Aid for Scientific Research from the Ministry of Education, Culture, Sports, Science and Technology of Japan (Grant nos. 23688041 and 15K14905).

\section{References}

1. Kirk TK, Fenn P (1982) Formation and action of the ligninolytic system in basidiomycetes. In: Hedger JN, Swift MJ (eds) Decomposer basidiomycetes Frank land JC. Their biology and ecology Cambridge. University Press, New York, pp 67-90

2. Gao D, Du L, Yang J, Wu WM, Liang H (2010) A critical review of the application of white rot fungus to environmental pollution control. Crit Rev Biotechnol 30:70-77

3. Wilson SC, Jones KC (1993) Bioremediation of soils contaminated with polynuclear aromatic hydrocarbons (PAHs): a review. Environ Pollut 88:229-249

4. Effmert U, Kalderas J, Warnke R, Piechulla B (2012) Volatile mediated interactions between bacteria and fungi in the soil. $\mathrm{J}$ Chem Ecol 38:665-703

5. Zou CS, Mo MH, Guy Q, Zhou JP, Zhang KQ (2007) Possible contributions of volatile producing bacteria to soil fungistasis. Soil Biol Biochem 39:2371-2379

6. Garbeva P, Hordjik C, Gerards S, De boer W (2014) Volatilemediated interactions between phylogenetically different soil bacteria. Front Microbial 5:289

7. Kobayashi DY, Crouch JA (2009) Bacterial/fungal interactions: from pathogens to mutualistic endosymbionts. Annu Rev Phytopathol 47:63-82

8. Wargo MJ, Hogan DA (2006) Fungal-bacterial interactions: a mixed bag of mingling microbes. Curr Opin Microbiol 9:359-364

9. Cespedes R, Salas L, Calderon I, Gonzales B, Vicuna R (1992) Microbial and biochemical-characterization of a bacterial consortium isolated from decaying wood by growth on a $\beta-O-4$ ligninrelated dimeric compound. Arch Microbial 158:162-170

10. Clausen CA (1996) Bacterial association with decaying wood: a review. Int Biodeterior Biodegrad 37:101-107

11. Kamei I, Sonoki S, Haraguchi K, Kondo R (2006) Fungal bioconversion of toxic polychlorinated biphenyls by white-rot fungus $P$. brevispora. Appl Microbiol Biotechnol 73(4):932-40

12. Kamei I, Suhara H, Kondo R (2005) Phylogenetical approach to isolation of white-rot fungus capable of degrading polychlorinated dibenzo-p-dioxin. Appl Microbiol Biotechnol 69:358-366

13. Pengfei X, Toshio M, Kamei I, Kondo R (2011) Metabolism of organochlorine pesticide heptachlor and its metabolite heptachlor epoxide by white rot fungi belonging to genus Phlebia. FEMS Microbiol Lett 314:140-146

14. Kamei I, Yoshida T, Enami D, Meguro S (2012) Coexisting Curtobacterium bacterium promotes growth of white-rot fungus Stereum sp. Curr Microbiol 64(2):173-178

15. Kamei I (2017) Co-culturing effects of coexisting bacteria on wood degradation by Trametes versicolor. Curr Microbiol 74:125

16. Hiraishi A (1992) Direct automated sequencing of $16 \mathrm{~S}$ rDNA amplified by polymerase chain reaction from bacterial cultures without DNA purification. Lett Appl Microbiol 15:210-213

17. Murray AC, Woodward S (2003) In vitro interactions between bacteria isolated from Sitka spruce stumps and Heterobasidion annosum. Forest Pathol 33:53-67

18. Krull R, Wucherpfennig T, Esfandabadi ME, Walisko R, Melzer G, Hempel DC, Kampen I, Kwade A, Wittmann C (2013) Characterization and control of fungal morphology for improved production performance in biotechnology. J Biotechnol 163:112-123

19. Driouch H, Sommer B, Wittmann C (2009) Morphology engineering of Aspergillus niger for improved enzyme production. Biotechnol Bioeng 105:1058-1068

20. Deveau A, Palin B, Delaruelle C, Peter M, Kohler A, Pierrat JC, Sarniguet A, Garbaye J, Martin F, Frey-klett P (2007) The mycorrhiza helper Pseudomonas fluorescens BBc6R8 has a specific priming effect on the growth, morphology and gene expression of the ectomycorrhizal fungus Laccaria bicolor S238N. New Phytol 175:743-755

21. Maier A, Riedlinger J, Fiedler HP, Hampp R (2004) Actinomycetales bacteria from a spruce stand: characterization and effects on growth of root symbiotic and plant parasitic soil fungi in dual culture. Mycol Prog 3:129-136

22. Hogan D, Vik A, Kolter R (2004) A Pseudomonas aeruginosa quorum-sensing molecule influences Candida albicans morphology. Mol Microbiol 54:1212-1223

23. Kerr JR (1999) Pseudomonas aeruginosa pyocyanin and 1-hydroxyphenazine inhibit fungal growth. J Clin Pathol 52:385-387

24. Verginer M, Leitner E, Berg G (2010) Production of volatile metabolites by grape-associated microorganisms. J Agric Food Chem 58:8344-8350

25. Frey-Klett P, Garbaye J, Tarkka M (2007) The mycorrhiza helper bacteria revisited. New Phytol 176:22-36

26. Weise T, Kai M, Gummesson A, Troeger A, Von reuss S, Pipenborn S (2012) Volatile organic compounds produced by the phytopathogenic bacterium Xanthomonas campestris pv. Vesicatoria 85-10. Bellstein J Org Chem 8:579-596 